\title{
Modelling a Smart-Grid for a Solar Powered Electric Vehicle ${ }^{\star}$
}

\author{
F.J. Gómez * Luis J. Yebra** Antonio Giménez* \\ * CIESOL, Joint Centre of the University of Almería-CIEMAT. 04120, \\ Almería,Spain (e-mail:fgn891@inlumine.ual.es, agimfer@ual.es). \\ ** CIEMAT Research Centre. Plataforma Solar de Almería, 04200 \\ Tabernas, Almería, Spain (e-mail: luis.yebra@psa.es).
}

Keywords: Object oriented modelling, electric vehicles, dynamic modelling, automatic control.

\section{INTRODUCTION}

Mathematical approximations for dynamic modelling of a Smart-Grid used in a electric solar powered small vehicle are developed for model based control purposes. The objective of this paper is to present the first principles and mathematical approximations behind the systems from which the Smart-Grid is composed of, that are mainly: photovoltaic (PV) panel, other renewable sources, battery, $\mathrm{DC} / \mathrm{DC}$ converter, accessories, motor and regenerative brake. For this objective, the Modelica modelling language offers a complete set of capabilities well known so far and spread in the literature, and the main ideas behind it and, its evolution and description are detailed in (Cellier (1991); Åström et al. (1998); Fritzson P. (2004)). The Modelica Standard Library (MSL) provides an important quantity of proven models to be reused, some of which have been applied in the models presented in this work. For the simulations, the Modelica tool Dymola(c) (Elmqvist (2012)) has been used. This work is inspired in Dizqah et al. (2012).

Fig. 1 shows the experimental electrical vehicle eCARM used for model validation, developed in the University of Almería for research in Automatic Control.

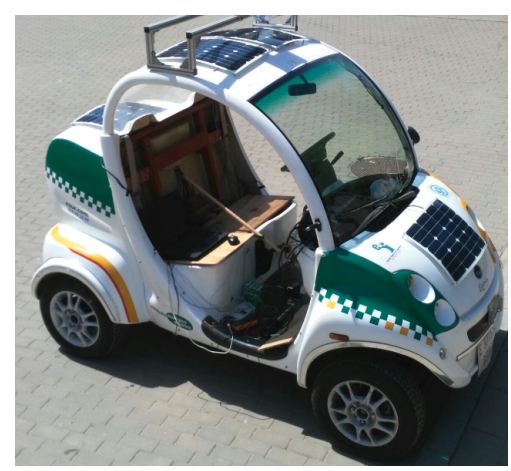

Fig. 1. eCARM: electrical vehicle used as test rig.

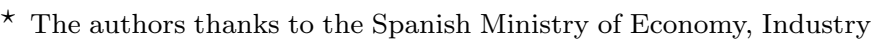
and Competitiveness and ERDF funds for partially funding this work.
}

\section{DESCRIPTION OF THE SMART-GRID}

This section presents the Smart-Grid composition for the solar powered small vehicle. The main components are shown in Fig. 2, where the electric power flows are represented by arrows.

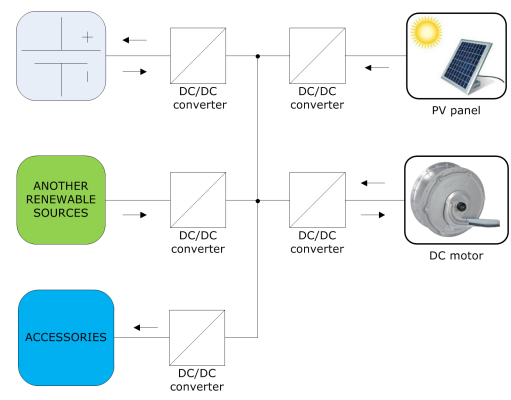

Fig. 2. Schematic diagram of the Smart-Grid modelled.

The bus receives power from battery, PV module and DC motor (when working as regenerative brake); and sends power to DC motor (when working as motor) and other unidirectional accesories. Please, note that the exchange of power between the battery and the bus is bidirectional. The interface to all devices from the bus is implemented by a DC/DC converter working in unidirectional or bidirectional configurations, so special care has been taken in the selection of this component, and its model features are discussed in the context of the whole Smart-Grid model. All these model devices have been modelled and parameters from commercial solutions have been used in the presented simulations.

\section{DYNAMIC MODELLING AND SIMULATION OF THE SMART-GRID}

This section presents the main model developed that is composed of the different submodels forming the SmartGrid. All the models are implemented in the Modelica modelling language. Some of them are formulated in steady state conditions by the use of algebraic equations, p.e.: PV model. Others are formulated by differential and algebraic equations (DAE): the battery, the motor, the load and the DC-DC converter. The models of the components are not presented due to space availability in this document. 
Fig. 3 shows the schematic diagram representing the modelled Smart-Grid that is formed by the DC motor, DC/DC converter and a battery. The whole three components works in a bidirectional power flow capability: the DC motor (acting as a load or as a generator), the DC/DC converter (controlling the power flow in one or another direction), and the battery (discharging or charging). The motor electrical interface is connected to a battery through a bidirectional DC/DC converter. In the mechanical interface the motor is connected to a inertia representing the equivalent external load, that itself is connected to and quadratic friction representing the equivalent friction of the vehicle to the environment.

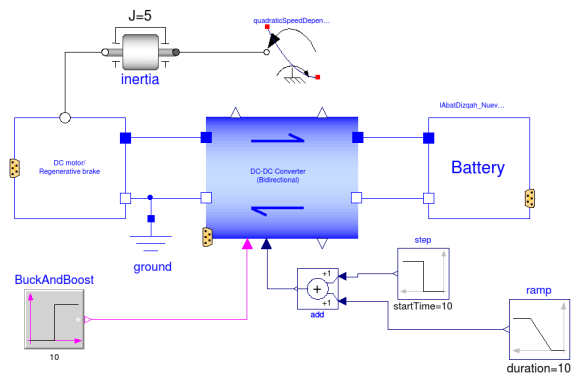

Fig. 3. Schematic diagram of DC motor working as a motor and a regenerative brake.

Simulation results of two experiments in this configuration are presented in Figs. 4 (1st experiment) and 5 (2nd experiment), in which power flow directions inversions are present. In both experiments, during the first $10 \mathrm{~s}$ the battery is discharging against the DC motor through the $\mathrm{DC} / \mathrm{DC}$ converter. In this time interval, due to the $\mathrm{DC}$ motor electrical power flow a mechanical torque is applied on the inertial load that is accelerated to a maximum angular velocity. After 10 s the DC converter power flow is switched back to battery, and the motor begins to work as a generator releasing power from the mechanical subsystem to the electrical one, that is, acting as a generator. This is the basic principle of the regenerative brake, although a more complex arrangement is usually required to implement a complete fully functional regenerative brake. From 10s onwards, while the motor behaves as a regenerative brake, the inertial load is decelerating. Power flow in the $\mathrm{DC} / \mathrm{DC}$ converter is inverted and now directed from brake (DC motor) to battery. The power flow can be deduced from the sign of the electrical intensity in variables DC_Converter_CurrentToBattery (current from DC converter to battery) and DC_Converter_CurrentToDCMotor (current from DC converter to DC motor) represented both in in Fig. 4. This figure additionally represents the angular velocity of the motor (omega). Fig. 5 represents additional electrical variables of the Smart-Grid in a second experiment: voltages at both sides of $\mathrm{DC} / \mathrm{DC}$ converter (battery and DC motor), battery charge (BatteryCharge) and duty cycle (DutyCycle) of the DC/DC converter.

\section{CONCLUSION}

A work in progress of a dynamic model for control design purposes of a Smart-Grid is presented. The model is composed of different components submodels, to be used in the hybrid solar powered experimental vehicle eCARM from

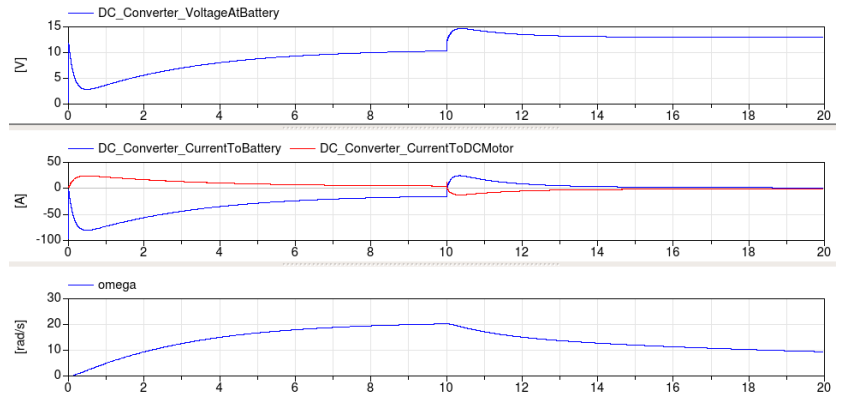

Fig. 4. Simulation of DC motor working in two modes: motor and regenerative brake. 1st experiment.

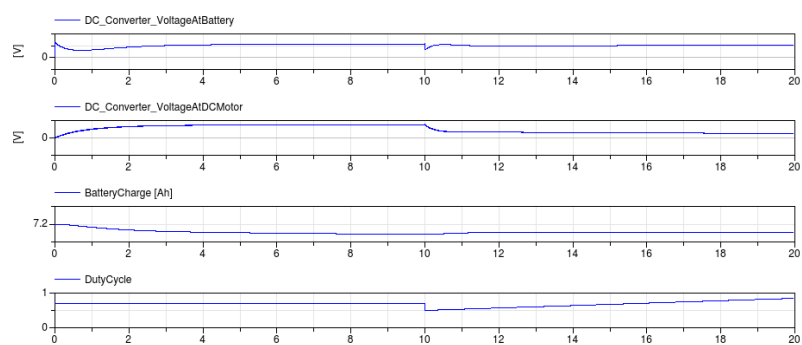

Fig. 5. Simulation of DC motor working in two modes: motor and regenerative brake. 2nd experiment.

University of Almería. The objective of the model is to be used in soft real time simulations and control applications in which the model will be used in complex controllers to be executed in real time. The main model representing the Smart-Grid has been presented and their modelling hypothesis outlined. All the information presented in this work comes from the bibliography sources referenced.

Future works are the calibration and validation of the models with experimental data from eCARM experimental electric vehicle.

\section{ACKNOWLEDGEMENTS}

This work has been funded by the National $\mathrm{R}+\mathrm{D}+\mathrm{i}$ Plan Project DPI2014-56364-C2-1/2-R of the Spanish Ministry of Economy, Industry and Competitiveness and ERDF funds.

\section{REFERENCES}

Cellier, F.E. (1991). Continuous System Modeling. Springer-Verlag New York, Inc., Secaucus, NJ, USA.

Dizqah, A.M., Busawon, K., and Fritzson, P. (2012). Acausal modeling and simulation of the standalone solar power systems as hybrid DAEs. In The 53rd International Conference of the Scandinavian Simulation Society (SIMS), 1-7.

Elmqvist, H. (2012). Dymola User Manual.

Fritzson P. (2004). Principles of Object-Oriented Modeling and Simulation with Modelica 2.1. Wiley-IEEE Press.

Åström, K.J., Elmqvist, H., and Mattsson, S.E. (1998). Evolution of Continuous-Time Modeling and Simulation. In R. Zobel and D. Moeller (eds.), Proceedings of the 12th European Simulation Multiconference, ESM'98, 9-18. Society for Computer Simulation International, Manchester, UK. 